\title{
Development of the teachers' creative competence by means of the development and implementation of an individual project
}

\author{
A.A. Smirnaya ${ }^{1 *}$, and A.V. Smirnova ${ }^{2}$ \\ ${ }^{1}$ Reshetnev Siberian State University of Science \& Technology, Krasnoyarsk, Russia \\ ${ }^{2}$ Krasnoyarsk State Pedagogical University named after V.P. Astafyev, Krasnoyarsk, Russia
}

\begin{abstract}
This article reveals the problem of the development of the teacher's creative competence. It also describes the pedagogical support for the development of the teacher's pedagogical creativity. A brief overview of issues related to the definition of the essence of pedagogical creativity, its specificity, and indicators is given. The study presents the substantiation of the problem proves its relevance for the development of the teacher's creative competence. The article presents the results of a comparative analysis of the development of the teacher's creative competence on the basis of Reshetnev Siberian State University of Science \& Technology (Krasnoyarsk) and Krasnoyarsk State Pedagogical University named after V.P. Astafyev (Krasnoyarsk).
\end{abstract}

\section{A problem statement}

At present, transformations are actively taking place in higher education. This is due to the fact that a modern student requires a "practice-oriented" education from the university, aimed at versatile personality development $[1,2]$. Consequently, a modern teacher must master a huge range of tools and means that provide high-quality training for future specialists capable of independently solving complex professional production and scientific problems. Modernization of the system of professional training of students of higher education [3-6] creates a need for the development of the teacher's creative competence, who will be able to improve the quality of professional training of future specialists, as well as teach students to perceive, understand, analyze and assimilate the transmitted information.

Thus, the main content of the presented article is focused on pedagogical support aimed at developing the teacher's creative competence. The development of this competence will allow teachers to reach a higher level of training in their professional activities.

\footnotetext{
* Corresponding author: prof-ped.gpa@mail.ru
} 


\subsection{The objective of the work}

The above problem is highlighted in the works of many scientists. Theoretical analysis of these works exploring the phenomenon of creativity (A.Sh. Amonashvili, V.I. Andreev, B.Z. Vulfov, L.S. Vygotsky, G.A. Davydova, V.V. Ignatova, T.V. Kudryavtsev, V.A. Levin, N.S. Leites, V.A. Molyako, Ya.A. Ponomarev, A.Z. Rakhimov, S.L. Rubinstein, A.G. Spirkin, V.A.I. Changli, A.P. Sheptulin, A.T. Shumilin, M.G. Yaroshevsky and others), showed that creativity is a sophisticated, complex, multifaceted, but at the same time, a coordinated, harmonious phenomenon $[7,8,9,4]$. Creativity is often characterized by a dual nature, which is in unity and integrity: practical and mental activity of transforming reality; can be generated by both the environment itself and the internal needs of the individual, that is, be its motivational and value guide. Hence, creativity acts as a value and as a result of the transformation of objective reality, and manifests itself as a personal characteristic. The works of researchers studying the phenomenon of creativity, creative potential, creative personality, and creative competence of a teacher formed the basis of this study. They made it possible to fill the theoretical basis of the research with content, which was supplemented by practical experimental data.

\section{Results of the research}

The development of the teacher's creative competence gives impetus to the development of the student's creative activity. The development of this competence makes it necessary to develop a pedagogical strategy of orienting the teacher to creative activity, which will consist in comprehensive pedagogical support aimed at orienting and developing the teacher's creative competence. It covers issues of theory and practice, preparation of a teacher for creative activity, its planning and conducting, explores the regularities of the creative process, develops forms, methods, techniques and means of pedagogical support, determines the goals and objectives of orienting and developing creative competence. The main idea of the pedagogical strategy is to develop the creative competence of a teacher of higher education and the professional growth of the individual. The implementation of this idea is one of the goals of higher education $[7,10,11]$.

Therefore we see our task in the creation of the necessary pedagogical support for the development of the teacher's creative competence, in particular, the creation of conditions, the choice of methods, techniques and means that ensure their effective influence on the process under study. In our understanding, pedagogical support acts as means, measures and mechanisms that make a certain pedagogical process possible, real, and actually feasible [12-14]. In this article, we focus on the study of the forms and methods of developing the teacher's creative competence and do not deeply examine the techniques and means of teaching.

An analysis of research in the field of didactics shows that the use of active teaching methods in the class leads not only to further individualization and intensification of the learning process, but also to significant structural shifts in the student's activity. Therefore, within the framework of our research, we will consider heuristic teaching methods that a teacher can use to implement his pedagogical activity.

Application of heuristic teaching methods is based on heuristic rules, heuristic techniques. Unlike formal logic, which is a method of acquiring knowledge, heuristic methods are designed to acquire knowledge when solving a problem, achieving a goal in a logical way is impossible [15]. Pedagogical methods designed to arrange heuristic approach for solving problems are aimed at teaching generalized ways of solving intellectual problems and developing productive thinking. The main goal is to teach the student to think, rebuild the information they know, complete the task, and develop intuition. The use 
of heuristic methods of cognition in solving an educational problem allows you to achieve the goal quickly and successfully without sequential enumeration of information.

V.I. Andreev gives the following classification of heuristic methods of educational and creative activity: direct collective "brainstorming", mass "brainstorming", "brainstorming" a dialogue with a destructive related assessment, the method of heuristic questions, the method of multidimensional matrices ("morphological box"), method of inversion, method of empathy (method of personal analogy), method of synectics. Brainstorming is a technique for stimulating creativity and productivity. The practice of using this technique led to skeptical assessments of its effectiveness, and experimental psychological testing did not confirm its advantages in solving creative problems [16]. Highly effective heuristic methods, such as the theory of inventive problem solving (TIPS), are of particular importance. Thus, an important result of the educational process carried out according to the system TIPS - pedagogy is the students' fairly frequent creation of new ideas, including those of scientific significance. All this contributes to the formation of knowledge, abilities and skills among students, making the educational process more interesting and emotional.

Moving in this direction, we will reveal heuristic methods that can be widely used by a teacher in teaching practice. For example, V.A. Dmitriev [17] proposes an advanced learning program and technology for its implementation; with this concept, the educational system can improve the quality of its graduates, expand the list of trained specialists, and strengthen its position in the educational services market. The basis of advanced learning is the organization of creative and inventive activity and heuristic research, which is essential for the consciousness of each person and realizes the mechanisms of changing the consciousness of a person and the world around him.

The greatest efficiency of the educational process is achieved in the context of enhancing the students' educational activities with an emphasis on interactive forms. Interactive learning is, first of all, dialogic learning, during which new knowledge is replenished as a result of the interaction of the teacher and the student, students with each other $[8,18]$.

Interactive learning has very specific and predictable goals. One of them is the creation of comfortable learning environment in which the student feels his success, his intellectual competence, which makes the learning process itself productive. We refer to group forms of learning the work of students in groups, analysis of specific situations, design and implementation of projects, free discussion. These forms of work are in fact interactive, since they consist of the exchange of information, as a result of which new educational information is produced.

A discussion is a sequential series of statements of its participants on the same issue, which provides the necessary coherence of the discussion. In most cases, the topic of the discussion is formed before it starts, which makes it possible for the participants to prepare for it more thoroughly. The goal of any discussion is to achieve in the given conditions the maximum possible agreement of its participants on the problem under discussion. The result of the discussion should be expressed in a more or less objective judgment supported by all participants of the discussion or the majority. Thus, in the discussion, a clearer and more precise characterization of the solution to the problem becomes apparent; the point of subjectivity is reduced, eliminated to a certain degree: the beliefs of one person or a group of people are objectified, acquiring certain validity $[18,17]$.

Small group work is effective in solving a practical problem (with different data) in the process of studying and consolidating a new topic. The project method, or the project based learning is a teaching method when the student independently states an educational problem, carries out a set of measures to solve it and brings his project to the defense. The project method is based on the development of students' cognitive skills, the ability to design their knowledge in dependently, the ability to navigate the information space, the 
development of critical and creative thinking. It is a set of techniques, operations of mastering a certain area of practical or theoretical knowledge, one or another activity [3].This is the way of cognition, the way of organizing the cognition process. The project method is based on the idea that constitutes the essence of the concept "project", its pragmatic focus on the result that can be obtained by solving a particular practically or theoretically significant problem.

If we talk about the project method as a pedagogical technology, then, firstly, this technology presupposes a set of research, search and problematic methods that are creative in their very essence. It is known that the method of analysis of specific situations has the greatest educational effect among the teaching methods used. Analysis of specific situations, or "case-study", allows you to go through the practice of solving strategic problems, gaining experience and awareness. Project activity is a process of communication "on equal terms", where all the participants in such communication are interested in it and are ready to exchange the information, express their ideas and solutions, discuss problems and defend their point of view. This is what reflects the communicative side of interactive learning, including the use of modern information technologies (distance learning).

Distance learning can be defined as the organization of the educational process, in which the teacher develops a curriculum based mainly on the student's independent learning. In general, the organization of distance learning is designed to solve specific problems related to the development of the creative component of education, the implementation of which is difficult in ordinary learning - strengthening the active role of the student in their own education: in setting learning goals, selecting directions, forms and pace of learning in various educational areas; a sharp increase in the amount of available information, access to the world's cultural and scientific treasures for students from any locality; obtaining an opportunity for a student to communicate with professional teachers, consultancy with high-level specialists, regardless of their territorial location; increasing the heuristic component of the educational process through the use of interactive forms of classes, multimedia training programs; creation of more comfortable conditions for creative self-realization of students, prospects for students to demonstrate the products of their creative activity for anyone interested, wide expert opportunities for their assessment.

Paired forms of interactive learning include work in pairs of line-up changes, various forms of peer learning and peer control, problem-search learning, etc. Group forms business and role-playing games, conversations, lectures with elements of discussion, research work, practical work. Work in pairs of line-up changes means such an organization of learning in which all participants work with each other in pairs and the pair's composition changes periodically. As a result, it turns out that each member of the educational team works in turn with each. It follows that all groups are created for a short time - exactly as long as they are allocated to solve the problem. For a certain period of time, each member of the group must work out his task, do self-study, train a partner and draw conclusions according to the goal. One of the forms of work in pairs of line-up changes is the "Interview". The task is to interview all members of the group in order to find out their opinion on the problem, to get answers to the questions stated. Then the general results, the results of the survey are discussed in group.

Conversation is a talk mainly between two people, hence, its participants can and should take into account the specific characteristics of the personality, motives, speech characteristics of each other, i.e. communication is largely interpersonal in nature and involves a variety of ways of verbal and non-verbal influence of partners on each other [14]. A conversation is not a monologue, but a dialogue, i.e. two-way communication, the purpose of which is either striving to better understand the nature of the problem that has arisen, or to influence one of the interlocutors, taking into account his interests and opinions on the issue under discussion. 
Organizational business games, as a rule, are long in time and require participants to use the necessary knowledge, skills and abilities. A business game is a pedagogical technique for modeling various managerial and production situations, with the aim of teaching individuals and groups to make decisions. Role play is a form of organizing group learning activities, with an aim at forming and developing skills and abilities in conditions as close to real ones as possible. It presupposes the distribution of roles among students and playing out communication situations in accordance with the topic of the lesson. In terms of time it is a relatively holistic cycle of controlled interaction between the teacher and students, which consists of three stages: preparation of role-playing games, its playing out, and group discussion of the results.

Summarizing the theoretical basis of pedagogical teaching methods that can be used by a teacher in his pedagogical practice, we turn to experimental research. The aim of the study was to define the manifestations of the teacher's creative competence in his professional activity.

From September 2020 to March 2021 on the basis of the Faculty of Foreign Languages of FSBEI HE "Krasnoyarsk State Pedagogical University named after V.P. Astafyev" (Department of English Philology) in Krasnoyarsk and the Institute of Social Engineering FSBEI HE "Reshetnev Siberian State University of Science \& Technology" (Department of Psychology and Pedagogy) in Krasnoyarsk, joint experimental work was organized and carried out, the purpose of which was to organize individual projects aimed at developing the creative competence of teachers. In the course of the experimental work with the aim of developing the creative competence of the teachers of the experimental groups, the development and implementation of an individual project in the discipline taught was organized.

During the development and implementation of an individual project, practical classes were held monthly in a distance-learning format. Teachers at a convenient time for them could get timely consultations on informational, organizational, and methodological issues. The estimated time spent on self-educational activities was determined by every teacher independently. The objectives of developing an individual project were: enriching the experience of developing an individual project, sharing experience of creative selfpresentation of a creative product, involving teachers in solving imitation situations of a creative character as a means of promoting creative self-affirmation, enriching the experience of creative self-presentation. The development and implementation of an individual project was aimed at developing the skill of solving imitative situations of a creative nature in the process of organizing a teacher's self-presentation of his creative product. Since the solution of imitation situations was completely creative in its character, a condition of absolute creative freedom was created, which contributed to the development of the teacher's creative potential, an increase in the level of his manifestation of creative independence, creative activity and creative self-efficacy, which in general led him to the maximum possible creative self-realization and affected mainly, organizational-activity and emotional-reflexive spheres of personality.

Development of an individual project is a stepwise process that includes the following levels: 1) the level of design of creative self-realization, depending on the specifics of the object under study, the significance and value for the teacher of the state of emotional uplift in the process of continuous professional self-education; 2) the level of self-affirmation, characterized by the use of the following productive methods: projects, setting the main goals and areas of activity, forecasting methods, theory construction, heuristic observation, heuristic research, heuristic questions, direct group brainstorming, synectics, induction, imitation situations of a creative nature, facts, synergy, goal-setting, planning reflection, reviews, control, reflection and self-esteem; 3 ) the level of creative self-presentation, based 
on reflection, perceived as the teacher's understanding of "by what means and why he made this or that impression on the communication partner" $[19,20]$.

The main objective of the development of an individual project in a discipline taught by a teacher we observed in the development of teachers' strong skills in choosing adequate methods, means, techniques and forms of self-presentation of the creative product they have designed and the development of creative competence.

In accordance with the goals and objectives of developing an individual project, in distance-learning classes the consultants of the creative laboratory informed teachers about modern technological means, various methods, techniques and forms of presenting a creative product. Situations were created with the aim of managing contact with the support of other teachers, sharing experience of self-presentation. In the conditions of a free choice of methods of creative self-presentation, teachers showed creative activity and creative independence. Thus, a gradual transition from imitative situations of a creative nature to situations of real pedagogical reality was carried out.

The basis for assessing the level of development of the creative competence of the experimental groups was the author's technique "Study of the teacher's creative competence" (Table 1). The essence of this technique consisted in the fact that the participants of the experimental work marked the manifestation of the creative indicator, in which the signs-quality of its manifestation was determined.

Table 1. Study of the teacher's creative competence.

\begin{tabular}{|c|c|c|}
\hline \multicolumn{3}{|c|}{$\begin{array}{l}\text { Dear teachers! We kindly ask you to study the creative indicator carefully and evaluate its } \\
\text { manifestation in professional activity based on your observations. } \\
\text { You can express your attitude in the pivot table as follows: mark the level of manifestation with a } \\
\text { certain symbol: X - characteristic for most signs; O - characteristic for individual signs; H - not } \\
\text { characteristic for individual signs. }\end{array}$} \\
\hline Indicator & Characteristics of the manifestation of the main signs & Evaluation \\
\hline \multirow{3}{*}{ Creative } & \multirow{3}{*}{$\begin{array}{l}\text { Flexibility, originality, ingenuity, curiosity, imagination, inspiration, } \\
\text { criticality, self-criticism, sensitivity to humor, sharpness, } \\
\text { resourcefulness, creativity, improvisation, professional mobility. }\end{array}$} & $\mathrm{X}$ \\
\hline & & $\mathrm{O}$ \\
\hline & & $\mathrm{H}$ \\
\hline
\end{tabular}

In order to transfer qualitative indicators into quantitative ones (which was necessary only for a more convenient comparison of the results), each level of manifestation of creative competence was contingently given points: $\mathrm{H}$ - not characteristic for individual signs - 1 point, $\mathrm{O}$ - characteristic for individual signs - 2 points, $\mathrm{X}$ - characteristic for most signs - 3 points. The average score of the general level of manifestation of the creative indicator was determined by the total score of all the main signs, divided by the number of people in the experimental group. In fact, an uneven mathematical scale was used, namely, the numeric value: from 3 to 6.9 points determined the non-characteristic (atypical) manifestation of social and pedagogical values for individual signs $(\mathrm{H})$; from 7 to 10.5 points - characteristic manifestation of individual signs $(\mathrm{O})$; from 10.6 to 12 points characteristic manifestation for most signs (X).

In the course of the experimental work, it was revealed that the development of an individual project contributes to the development of the teacher's creative competence, which includes such qualities as originality of thinking, improvisation, receptivity to new things in activity and innovation, flexibility in decision-making, ingenuity, inspiration, criticality, resourcefulness and creativity. The reliability and validity of the results obtained is ensured by: checking the results of the study at its different stages (ascertaining and control). Here we present comparative data on the level of creative competence of teachers of the experimental groups at the beginning and end of the experimental work at FSBEI HE "Krasnoyarsk State Pedagogical University named after V.P. Astafyev" (Department of English Philology) in Krasnoyarsk and the Institute of Social Engineering FSBEI HE 
"Reshetnev Siberian State University of Science \& Technology" (Department of Psychology and Pedagogy) in Krasnoyarsk (Table 2).

Table 2. Change in the level of manifestation of the creative indicator of the teachers of the experimental groups during the implementation of the individual project in points (the beginning and the end of the experiment).

\begin{tabular}{|c|c|c|c|c|c|c|c|c|c|c|c|c|c|}
\hline \multirow{2}{*}{\multicolumn{2}{|c|}{$\begin{array}{c}\text { GROUPS } \\
\text { (total } 74 \\
\text { persons) }\end{array}$}} & \multicolumn{5}{|c|}{$\begin{array}{c}\begin{array}{c}\text { The beginning of the } \\
\text { experiment }\end{array} \\
\text { Levels }\end{array}$} & \multirow{2}{*}{\multicolumn{2}{|c|}{$\begin{array}{c}\text { GROUPS } \\
\text { (total } 69 \text { persons) }\end{array}$}} & \multicolumn{5}{|c|}{ The end of the experiment } \\
\hline & & \multirow{2}{*}{$\begin{array}{l}n_{0}^{\infty} \\
x \\
x\end{array}$} & \multirow{2}{*}{ 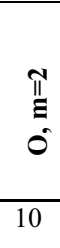 } & \multirow{2}{*}{$\begin{array}{l}\underset{\Xi}{\mathbb{I}} \\
15\end{array}$} & \multirow{2}{*}{ 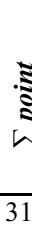 } & 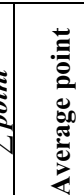 & & & \multirow{2}{*}{$\frac{\substack{\| \\
\Xi \\
x}}{33}$} & \multirow{2}{*}{$\begin{array}{l}\pi \\
0 \\
0 \\
0\end{array}$} & \multirow{2}{*}{$\begin{array}{l}\stackrel{\pi}{\Xi} \\
\dot{=} \\
2\end{array}$} & $\Xi$ & 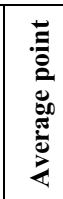 \\
\hline \multirow{2}{*}{$\begin{array}{c}\text { EG- } \\
1 \\
22 \\
\text { pers. }\end{array}$} & Snoint & & & & & 1.40 & \multirow{2}{*}{$\begin{array}{c}\text { EG-1 } \\
22 \\
\text { pers. }\end{array}$} & Snoint & & & & \multirow[t]{2}{*}{53} & \multirow[t]{2}{*}{2.41} \\
\hline & pers. & 2 & 5 & 15 & & & & pers. & 11 & 9 & 2 & & \\
\hline \multirow{2}{*}{$\begin{array}{c}\text { EG- } \\
2 \\
25 \\
\text { pers. }\end{array}$} & Epoint & 6 & 16 & 15 & \multirow[t]{2}{*}{37} & \multirow[t]{2}{*}{1.48} & \multirow[b]{2}{*}{$\begin{array}{l}\text { EG-2 } \\
23 \\
\text { pers. }\end{array}$} & Epoint & 33 & 14 & 5 & \multirow[t]{2}{*}{52} & \multirow[t]{2}{*}{2.26} \\
\hline & pers. & 2 & 8 & 15 & & & & pers. & 11 & 7 & 5 & & \\
\hline \multirow{2}{*}{$\begin{array}{c}\text { EG- } \\
3 \\
27 \\
\text { pers. }\end{array}$} & Spoint & 3 & 14 & 19 & \multirow[t]{2}{*}{36} & \multirow[t]{2}{*}{1.33} & \multirow{2}{*}{$\begin{array}{l}\text { EG-3 } \\
24 \\
\text { pers.. }\end{array}$} & Spoint & 24 & 22 & 5 & \multirow[t]{2}{*}{51} & \multirow[t]{2}{*}{2.13} \\
\hline & pers. & 1 & 7 & 19 & & & & pers. & 8 & 11 & 5 & & \\
\hline \multirow{2}{*}{$\begin{array}{l}\text { Total } \\
74 \\
\text { pers. }\end{array}$} & Spoint & 15 & 40 & 49 & \multirow[t]{2}{*}{104} & \multirow[t]{2}{*}{1.41} & \multirow{2}{*}{$\begin{array}{l}\text { Total } \\
69 \\
\text { pers. }\end{array}$} & Spoint & 90 & 54 & 12 & 156 & 2.27 \\
\hline & pers. & 5 & 20 & 49 & & & & pers. & 30 & 27 & 12 & & \\
\hline & oint & & & 104 & & & & & & & 56 & & \\
\hline Ave & epoint & & & 1.41 & & & Aver & point & & & 27 & & \\
\hline
\end{tabular}

For visual tracking of dynamics of the distribution of teachers in the experimental groups according to the manifestation of the creative indicator, we present the results of studying these values for all indicators in percentage (Table 3).

Table 3. Distribution of teachers of the experimental groups according to the level of manifestation of the creative indicator (beginning and end of the experiment in \%).

\begin{tabular}{|l|l|c|c|c|}
\hline \multicolumn{2}{|l|}{ Control estimation } & \multicolumn{3}{|l|}{$\begin{array}{l}\text { Indicator and levels of its manifestation (X - characteristic for } \\
\text { most of the signs, O- characteristic for individual signs, H - not } \\
\text { haracteristic for individual signs) }\end{array}$} \\
\cline { 2 - 5 } & \multicolumn{3}{|c|}{ creative } \\
\cline { 2 - 5 } \multicolumn{2}{|c|}{} & $\mathbf{X}$ & $\mathbf{O}$ & $\mathrm{H}$ \\
\hline \multirow{2}{*}{$\begin{array}{l}\text { Beginni } \\
\text { ng }\end{array}$} & 74 pers. & 5 & 20 & 49 \\
\cline { 2 - 5 } & $\%$ & 6.8 & 27 & 66.2 \\
\hline \multirow{2}{*}{ Ending } & 69 pers. & 30 & 39.1 & 12 \\
\cline { 2 - 6 } & $\%$ & 43.5 & 27.4 \\
\hline
\end{tabular}

The results obtained indicate that the number of teachers with the level of manifestation of creative competence increased for all indicators at the level " $\mathrm{X}$ " characteristic for most signs" at the end of the experimental work in comparison with its beginning - from $6.8 \%$ to $43.5 \%$.

Thus, the significant positive dynamics of the manifestation of the creative indicator among the teachers of the two universities confirms the effectiveness of the experimental work carried out. 


\section{Conclusions}

According to the analysis of the theoretical base and experimental work, it was revealed that the development of the creative competence of teachers is a vector of orientation of students towards the development and self-development. In the process of professional training of students, a creative teacher is able to present diverse material for information processing, switch from one form of lesson to another quickly, taking into account the request of students, which in general contributes to the high-quality assimilation of knowledge.

The development and implementation of an individual project initiated the development of the teacher's creative competence. Of course, it is necessary to understand that the development of the creative component is a long-term process. The inclusion of teachers in the implementation of their project in the discipline taught is the first stage in our study, which already has positive dynamics. Consequently, including teachers in the modern creative process will significantly improve the quality of the higher education system.

\section{References}

1. V. Knyaginin, Competence approach and post-industrial labor market, Center for strategic development "North-West", 4, 32 (2005)

2. N.N. Tulkibaeva, Z.M. Bolshakova, E.V. Gnatyshina, R.F. Kovtun, A.M. Vitt, I.V. Zhuzhgova, S.A. Stolyarova, N.S. Strixhkova, Educational management: theory and practice: Collective monograph, 138 (2018)

3. Z.R. Amet Usta, S.A. Vovk, Modern educational technologies, Modern problems of science and education, 6 (139), 92-95 (2019)

4. V. Knyaginin, N. Trunova, Competence approach and post-industrial labor market, Center for strategic development "North-West", 4, 32 (2005)

5. Yu.G. Tatur, Competence in the structure of the quality model of training specialists, Higher education today, 3, 21-26 (2004)

6. T.B. Feiling, Modern educational technologies in additional professional education, Izvestiya RSPU named after A.I. Herzen, 44, 485-489 (2007)

7. V.V. Ignatova, M.G. Shishkova, Orienting students of vocational schools to creative self-realization as a pedagogical strategy, Vestnik Tomsk State University, 340, 180$183(2010)$

8. V.V. Ignatova, S.S. Yuferev, Performing culture of the future bachelor: criteria and levels of its formation, Modern studies of social problems, 10, 46-55 (2016)

9. V. Knyaginin, Competence approach and post-industrial labor market, Center for strategic development "North-West", 4, 32 (2005)

10. V.V. Ignatova, E.Yu. Pimenova, Criteria for the formation of the spiritual and creative potential of students in the space of additional education, Science and school, 6, 212-220 (2020)

11. A.V. Kutuzova, Activization of creative activity of students in the context of the implementation of standards of the third generation, Psychology and pedagogy: methodology and problems, 25-2, 53-58 (2012)

12. V.V. Ignatova, L.A. Baranovskaya, Spiritual and creative formation of the personality and its social responsibility: monograph, 81 (2010) 
13. V.V. Ignatova, A.V. Kichigina, Preparing a student for co-creative activity on the basis of a competence-based approach-the reality of third-generation standards, Basic research, 12-1, 31-35 (2011)

14. S.S. Yuferev, V.V. Ignatova, T.V. Furyaeva, Scientific validity of developing diligence in future bachelors, The World of Academia: Culture, Education, 7, 36-42 (2019)

15. S.N. Martynovskaya, S.N. Dolmatov, N.V. Sukhenko, Research of criterion characteristics of creative potential of students of technical universities, The era of science, 15, 201-204 (2018)

16. G.S. Altshuller, Find an idea. Introduction to the TRIZ theory of inventive problem solving, 202 (2007)

17. O.P. Popova, On the question of the problems of modern professional education, Modern problems of science and education, 100-101 (2003)

18. M.Yu. Oleshkov, Pedagogical technology: the problem of classification and implementation, Professional and pedagogical technologies in the theory and practice of training: Collection of scientific papers, 5-19 (2005)

19. A.A. Smirnaya, A.V. Smirnova, Analysis of the basic socio-pedagogical values of a humanitarian graduate, Problems of modern pedagogical education, 68-4, 194-197 (2020)

20. I.S. Yakimanskaya, The foundations of personality-oriented education, BINOM, 220 (2013) 